\title{
Happiness in the Workplace
}

\author{
Nesreen Ibrahim Awada, Fadillah Ismail
}

\begin{abstract}
Recently, the United Arab Emirates (UAE) government has worked towards establishing a national program for happiness and wellbeing. Workplace-related happiness has become a topic of interest in today's employment world. Administrators need to look at the ingredients within the recipe to address happiness and happiness in an organization. However, in the Middle East Region, there is still the absence of an empirical Islamic happiness scale which also encapsulates the spiritual and emotional wellness element, employee happiness and performance in one scale. Also, empirical studies on employee spiritual and emotional happiness at work are still lacking. Thus, the researcher will explore these ideas in greater detail This paper reviews what is known about the definition, causes and consequences of happiness at work, The interest in happiness has also extended to workplace experiences. drawing also on insights from the expanding positive psychology literature on happiness in general. Happiness at work includes, but is far more than, job satisfaction. A comprehensive measure of individual-level happiness might include work engagement, job satisfaction, and effective organizational commitment. We will be focusing on happiness Importance and Impact of Happiness at Work by highlighting the Advantages \& Disadvantages.
\end{abstract}

Index Terms: Employee, Happiness, Management, Workplace.

\section{INTRODUCTION}

Globally, the concept of happiness management is gaining attention. Thus, the trend is not new. In the previous decades, one of the crucial roles of the human resource 9HR) personnel involved workforce motivation. Currently, the functions and motivations stretch beyond financial operations to focus on the employees' overall well-being, as the latter factor shapes their productivity; hence firm profitability. The study by Al Maktoum (2017) pointed out differences between societal and personal happiness. Indeed, it was established that happiness as a concept refers to a state in which individuals or workforces feel comfortable, secure, and safe. By providing room for the workforces to maintain good well-being, organizations tend to improve the team members' involvement in work operations. It is also notable that in the workplace, happiness is linked to spirituality in which team members are keen to realize the transcendence, self-knowledge, and meaning towards higher-level performance and operation (Petchsawang \& Duchon, 2009, p. 460). Upon achieving meaning and purpose in life and the workplace, most of the team members end up feeling better, hence improved

Revised Manuscript Received on July 22, 2019

Nesreen Ibrahim Awada, Department of Production and Operations Management, Faculty of Technology Management and Business, Universiti Tun Hussein Onn Malaysia (UTHM).

Fadillah Ismail, Department of Production and Operations Management, Faculty of Technology Management and Business, Universiti Tun Hussein Onn Malaysia (UTHM). productivity - that poses a trickle-down effect of increased firm profitability.

\section{LITERATURE REVIEW}

Several sources were used in this research of workplace happiness that helps define the concept in question and develop an understanding of elements that contribute to it. Maktoum's (2017) book provides an understanding of the different aspects of happiness, including personal and societal, which provides implications for investigation individual's satisfaction in the context of interactions with others. Additionally, this work explains the model of happiness that can be achieved through proper life habits such as positivity, providing implications for organizations to create environments that foster this attitude.

The culture that guides interactions of employees within companies can be altered to enhance happiness by applying appropriate models of happiness. The article by Bader, Hashim, and Zaharim (2013) examines the topic of friendship in the workplace as an element that helps foster happiness within organizations. The findings contribute to this research by providing implications for understanding interpersonal communications within a work environment. Liu and Robertson (2011) article examine theoretical concepts and approaches to spirituality in firms, which can be used for developing a scale that can be used to measure the attitudes of individuals towards perceived higher power, nature, and other people, while Pawar (2008) discusses the concept as a whole. The findings of this literature imply that ethics, believes, and values are critical for commercial organizations in regards to happiness.

The examined literature provides an understanding of the complex nature that facilitates workplace happiness. A study conducted by Petchsawang and Duchon (2009) argues that spirituality contributes to the feeling of happiness at a workplace. This includes mindfulness and compassion, which allows one to understand the specifics of developing an appropriate environment by creating a connection between an organization and its employees that will provide the latter with the feeling of confidence and safety. Dimitrov's (2012) contributed to this paper by expanding an understanding of meaningfulness at work. Apart from the workflow and quality of product or service participants of the author's study cited social environment and specifics of their organization as elements that contribute to their happiness. Samnani and Sign (2014) argue that standard practices applied by companies to enhance employee performance, for instance, compensation based on productivity, may have adverse impact on the staff members, while Hosie and Sevatos (2009), as well as Joo and Lee (2017), argue that 
employers can affect the productivity of work within their organizations. However, the focus should be not only on financial compensation but also on the wellbeing of individuals.

A research conducted in a real-life work environment helps to understand the connection between organizational attitudes and happiness, which contribute to this paper's conclusions. Thompson and Goodale (2006) state that the proper planning of the workflow is crucial and should consider individual specifics of employees. Therefore, there is no single strategy that can guarantee workplace happiness and companies have to incorporate different elements that help enhance workplace happiness.

\section{RESEARCH METHODOLOGY}

The research methodology for this study incorporated an examination of various sources such as books and journal articles that discuss happiness in general and organizational strategies for fostering an appropriate environment. Additionally, several studies, such as Bader et al. (2013), Petchsawang and Duchon (2009), and Dimitrov (2012) that provide evidence-based practices for companies are discussed in this paper. These works help understand the concept of happiness and its correlation with interpersonal relationships such as friendships and communication, as well as its connection with organizational attitudes and values.

\section{CONCEPT OF HAPPINESS AT WORK}

Given that it is not a new trend, happiness as a concept has continually gained attention, hence growing global popularity. Previous, most of the human resource (HR) personnel functions revolved around the practice of employee motivation. Currently, the functions stretch beyond financial operations to include the workforces' overall well-being in the workplace. The study by $\mathrm{Al}$ Maktoum (2017) indicated that there is a difference between societal and personal happiness. Also, it was indicated that happiness constitutes a state in which members of the team feel comfortable, secure, and safe in a given setting; including the workplace. Should a firm provide room for the team members to maintain desirable levels of well-being, the workforces are likely to be more involved or engaged in work activities. Also, happiness is seen as a spiritual aspect through which team members are keen to realize higherlevel transcendence, as well as deeper self-knowledge and meaning. (Petchsawang \& Duchon, 2009, p. 460). Вy finding meaning and understanding one's purpose in a given scenario, happiness ensures that the individuals (such as employees gain motivation towards successful and effective role performance, as well as task completion.

\section{A. Importance and Application of the Topic}

Given the stiff competition and state of economic uncertainty, workplace happiness has gained growing attention in organizations. Currently, the need for tam leaders to ensure that there is employee (Dimitrov, 2012). Specifically, happy team members have been documented to be better placed to understand their roles and responsibilities, as well as participate in the required tasks actively. Such employees feel involved and also responsible. This observation points to the criticality of ensuring that the workforces are well motivated and inspired towards realizing new achievements in the organizations to which they are attached. The eventuality is that happy employees are better placed to realize successful problem-solving. It is also worth noting that the motivation of employees, which tends to make them happy, needs to be both non-material and financial; especially by assuming paths through which the team members could anticipate personality development and career advancement.

It is also worth indicating that happiness in the workplace applies to different scenarios. The scenarios range from first-line workers to the managers and other senior leaders. In the study by Bader, Hashim, and Zaharim (2013), the main aim was to find out the role of workplace friendship in shaping operations among employees in the banking sector. In the findings, it was reported that when positive interpersonal relationships are emphasized, the employees feel motivated and engaged. However, the authors cautioned that several factors play a moderating or predictive role in shaping this relationship. Factors that were documented include education level, gender, and age. In particular, it was established that male employees are more likely to embrace friendships in the workplace than their female counterparts. These results concurred with those that were reported by Bader et al. (2013), who noted further that further that employees who are aged 40 and above are more likely to embrace friendships in the workplace. Regarding the parameter of education level, most of the current literature contends that individuals with secondary education tend to establish more friendships than their counterparts with higher education diplomas. Hence, the insights point to the need for further research about the role of different demographic features in shaping workplace happiness. Furthermore, the examinations aid in establishing or developing and implementing relevant strategies through which happiness in the workplace could be improved, having understood major factors that play a positive and predictive role in realize the state of happiness; a predictor of improved productivity.

The concept of happiness in the workplace has also been studied in relation to some of the challenges that HR specialists face; especially during the development, retention, and hiring of workforces. Given that the current workplace environment is changing rapidly, it becomes notable that many companies are in a continuous struggle to attract and retain talented employees (Dimitrov, 2012). Hence, there is a need to pay attention to the intrinsic factors responsible for employee motivation, upon which the HR groups might gain knowledge about relevant strategies that could aid in unearthing and building on the intrinsic forces that the employees exhibit. In the investigation by Dimitrov (2012), it was established that a company such as Patagonia does not emphasize market pressure as a driving force towards implementing relevant employee motivation strategies. Rather, being environmentally conscious and human friendly play a key role towards the attraction and retention of the top talent. The eventuality is that selfactualization techniques and 
non-monetary measures play a key role in shaping the success of workforce motivation.

For the management, participation aids further in building employee happiness. In the investigation by Hosie and Sevastos (2009), it was noted that happiness requires individualization. Also, it was noted that when employees are talented, making them happy makes them to feel valuable and prompts them to refine their skills. However, the situation requires a balance because the employers find themselves caught up between realizing company profitability and benefiting the employees through happiness (Hosie \& Sevastos, 2009). Should discomfort among the workforces arise, there is likely to be imbalanced work, which is associated with frustrations, delayed deadliness, and poor performance; yielding reductions in firm profitability. the situations is compounded by a possible presence of rigid employees who might be resistant to change.

Indeed, each member of the team is likely to strive towards harmonious working; ensuring further that they build successful relationships with other workforces. However, the process requires personal values to be aligned to the goals of the rest of the team or organization. For leaders, it is important to establish workplace environments that allow the employees to pay attention to and develop a shared vision. in so doing, there is likely to be a linkage between the potential contribution of each employee and the intended short-term and long-term goals of the company (Hosie \& Sevastos, 2009). Impact of Happiness at Work

From the literature about the concept of employee welfare and how it affects firm productivity, most of the findings suggest that when the well-being of the employees improves, the overall performance of the company tends to improve; hence profitability. thus, improved well-being is seen to steer improvements in the quality of the services and goods offered, as well as productivity and the financial performance of the concerned firm. Hence, there is a need to implement programs that seek to improve the well-being of team members, ensuring that the psychological capital of the workforces is exploited optimally (PsyCap). Another factor that plays a complementary role in realizing the positive outcome entails the perceived organizational support (POS) (Joo \& Lee, 2017). Factors that shape the well-being of individuals are also worth considering. Examples include their contribution to society, physical condition, and financial status. For employees experiencing health challenges and other family problems, the provision of maximum energy and commitment or involvement in the workplace tend to be compromised.

Indeed, many scholarly investigations have strived to unearth the impact that the attribute of happiness poses on the productivity of employees but little has been done relative to the understanding of the extent to which different professions and positions shape the correlation (or play a moderating role). In the study by Joo and Lee (2017), committed and engaged employees were associated with higher PsyCap and POS. The factor that played a mediating role in shaping this link was work engagement. Hence, the results increase the understanding of the beneficial effect of workplace happiness in steering improvements in organizational performance. For organization managers and other senior leaders, it becomes important to implement strategies such as those that involve the provision of opportunities for employee development of own competencies, growth, and the provision of solutions to any individual and family problems that hinder happiness and, in turn, compromise productivity in the workplace. With satisfaction in the workplace achieved by the aforementioned strategies, improvements in firm productivity are likely to be realized; especially with the employees "owning" the company and feeling valued and wanted in the workplace - that caters for their well-being.

Similarly, employees who hold positive attitudes towards leaders and management have been observed to exhibit increased productivity. According to Al Maktoum (2017), there is a direct relationship between positivity and happiness. Thus, organizations ought to embrace employee happiness programs to ensure that members of the team are optimistic, rather than express the intention to quit. By implementing relevant strategies that could make the workforces happy and engaged in the workplace, Al Maktoum (2017) stated that there is likely to be an increase in firm profitability, a secondary effect accruing from improved productivity at the organization level.

\section{B. Advantages}

From the literature, happiness in the workplace poses several beneficial effects. The effects range from physical to social aspects (Al Maktoum, 2017, p. 23). Particularly, happy employees are more likely to be inspired to accommodate changes in the workplace, besides understanding and accomplishing the roles and responsibilities expected of them. Also, companies that cater for the well-being of their employees gain benefits by achieving an atmosphere marked by respect and trust, besides team-work and idea sharing. Also, happy employees are more likely to give opinion during team sessions as they feel valued and anticipate reinforcements. It is also worth indicating that a friendly workplace environment, a product of employee happiness paves the way for high-quality communication and socialization. Similarly, happiness ensures that the target personnel are attentive to instructions and comply with privacy and work-balance requirements. Overall, the members feel relaxed because of the resultant work-life balance in which adequate time is spent both in the workplace and home settings.

Another beneficial effect with which workplace happiness is associated involves the realization of corporate spiritual values. According to Pawar (2008), happiness allows for connectedness in the workplace, hence harmony among team members. In addition, there is likely to be superior performance among happy employees because happiness reduces turnover rates and, instead, increases firm profitability (Pawar, 2008, p. 558). Hence, happiness in the workplace is seen to introduce a sense of purpose in which workforces feel relevant and also perceive their contribution to the organization as that which is well acknowledged (Liu \& Robertson, 2011). The beneficial outcome becomes more pronounced when members of the team realize that the organizations with which they 
work are not only engaged in the implementation of employee happiness programs but also strive to engage in corporate social responsibility initiatives that seek to benefit the communities in which they operate - or to which they belong.

Physically, happy employees have been documented to exhibit a feeling of security. Also, happy employees tend to have enough sleep, access quality health care services, and also participate in physical exercising; having found themselves living stress-free life. For senior leaders and managers of organizations, it becomes important to implement employee happiness programs. In situations involving multitasking, high workload and constant stress, it remains notable that negative effects tend to arise. These effects include poor health and non-commitment to the workplace; which translate to delayed deadlines - as work plans are poorly designed. To make the employees happy, some of the specific programs that are worth implementing include those that encourage smoking cessation, engagement in weight loss programs, and the promotion of nutritious and healthy mal programs. With healthy lifestyles realized, employee happiness is likely to dominate the concerned workplaces, hence improved productivity - and increase profitability.

Lastly, Petchsawang and Duchon (2009) noted that happiness in the workplace attracts a sense of spirituality, which is marked by meaningful work, transcendence, compassion, and mindfulness. With improvements in one's sense of spirituality, a product of workplace happiness, it becomes inferable that the attribute makes members of the team to feel motivated and valued, eventuality gaining engagement, rather than express the intention to quit.

\section{Disadvantages}

Separate employee welfare programs are a good initiative, but they cannot provide the desired effect. Instead, it is critical to follow a systematic approach to introducing employee happiness initiatives and assessing their results. It will not only allow adjusting the process of working with employees but also to monitor the effectiveness of initiatives and business benefits. In order not to turn well-being management into an excessively tense HR activity, interviews with employees seem to be helpful to determine priorities and expected benefits. Since many companies fail to properly plan and introduce workplace happiness programs, the identified issue can be considered a disadvantage. It is recommended to develop a comprehensive program and involve the company's top management in its implementation.

The second disadvantage may be determined as a lack of attention paid to taking care of the financial well-being of employees. It is significant to keep in mind that although happiness is not about money, employees should be able to cover their basic needs, pay for housing, relax, have desired leisure activities, and take care of their health (Samnani \& Singh, 2014). It seems essential to point out the fact that in an attempt to ensure that employees have non-monetary compensation, many companies fail to pay fair and competitive remuneration. Therefore, it is critical to provide people with decent wages, educate them on financial literacy, and form a fund to help those who are in a difficult financial situation.

Another possible demerit is that productivity is elative and is likely to vary based on predictive factors such as employee competency, skill, and knowledge. According to Thompson and Goodale (2006), employees exhibiting lower productivity, upon being underestimated, could cause scheduling errors. Hence, planning and implementing employee happiness programs calls for the strengths and weaknesses with which each individuals comes in the workplace; rather than implement a standard program. Hence, implementing standard employee happiness programs poses a dilemma because the decision is unlikely to appeal to all members of the team, especially because most of the current organizations house multicultural teams with each team members embracing varying needs and preferences - on what makes them happy (or otherwise).

\section{CONCLUSION}

In summary, happiness in the workplace poses several beneficial effects and prompts senor organization leaders and managers to implement empowerment programs. By implementing relevant programs, there is likely to be an improvement in productivity, as well as an increase in firm profitability. some of the constructs that predict employee happiness include friendship, communication, and compassion. Hence, the leaders and managers ought to clarify the vision for the future, as well as make employees understand the purpose and significance of their work. Some of the specific benefits that accrue from workplace happiness include the willingness to participate actively in team activities, engagement ion work-related processes, and increased productivity; besides reduced chances of employee turnover - and the realization of work-life balance among members of the team. However, workplace happiness comes with its costs because it requires the development and implementation of comprehensive programs through which the established happiness could be maintained and extend it into the far future of the operations of the affected firms.

\section{ACKNOWLEDGMENT}

The paper is fully supported by the Faculty of Technology and Business Management, UTHM. A very high appreciation to Muhamad Yusnorizam Ma'arif from Universiti Kebangsaan Malaysia (UKM) who assist on the formatting and proofreading of this manuscript.

\section{REFERENCES}

1. Al Maktoum, M. B. R. (2017). Reflections on happiness \& positivity. Dubai, UAE: Explorer Publishing.

2. Bader, H. A., Hashim, I. H., \& Zaharim, N. M. (2013). Workplace friendships among bank employees in Eastern Libya. Digest of Middle East Studies, 22(1), 94-116.

3. Dimitrov, D. (2012). Sources of meaningfulness in the workplace: A study in the US hospitality sector. European Journal of Training and Development, 36(2/3), 351-371.

4. Hosie, P. J., \& Sevastos, P. (2009). Does the "happy-productive worker" thesis apply to managers? International Journal of Workplace Health Management, 2(2), 131-160.

5. Joo, B. K., \& Lee, I. (2017) Workplace happiness: Work engagement, career satisfaction, 
and subjective well-being. Evidence-based HRM: A Global Forum for Empirical Scholarship, 5(2), 206-221.

6. Liu, C. H., \& Robertson, P. J. (2011). Spirituality in the workplace: Theory and measurement. Journal of Management Inquiry, 20(1), 3550.

7. Pawar, S. B. (2008). Two approaches to workplace spirituality facilitation: A comparison and implications. Leadership \& Organization Development Journal, 29(6), 544-567.

8. Petchsawang, P., \& Duchon, D. (2009). Measuring workplace spirituality in an Asian context. Human Resource Development International, 12(4), 459-468.

9. Samnani, A. K., \& Singh, P. (2014). Performance-enhancing compensation practices and employee productivity: The role of workplace bullying. Human Resource Management Review, 24(1), 5 16.

10. Thompson, G. M., \& Goodale, J. C. (2006). Variable employee productivity in workforce scheduling. European Journal of Operational Research, 170(2), 376-390. 